\title{
Applications of monoclonal antibodies in the investigation, diagnosis, and treatment of retinoblastoma
}

\author{
John F Tarlton, D L Easty
}

In Europe and North America, retinoblastoma has a reported incidence ranging from 1 in 14000 to 1 in 36000 live births $^{1-5}$ and is the most common ocular malignancy affecting children and infants. Early diagnosis allows the application of a number of therapies directed at localised disease, including external beam and plaque radiotherapy, cryotherapy, and photocoagulation, although the principal treatment accounting for the high cure rate of around $90 \%$ is enucleation, which is still carried out in over half of all cases. The justification for such radical therapy is the poor prognosis once the tumour escapes the eye, and the high mortality from metastases. ${ }^{6}$

In the developing countries of Africa and Asia the picture is different. The higher reported incidence in many areas, ${ }^{7-11}$ coupled with a lower incidence of ocular malignant melanoma in particular racial groups results in retinoblastoma being the commonest ocular tumour in all age groups. Moreover, late diagnosis and treatment lead to a correspondingly high rate of mortality due to metastatic spread, approaching $100 \%$ in some areas. ${ }^{10}$

Therefore the inability to deal effectively with metastatic retinoblastoma results in a high mortality in areas where medical care is limited and the extensive use of prophylactic enucleation in developed countries. Despite the efficacy of current therapeutic intervention, there remains a need for further investigation into improvements in treatment of metastatic disease.

Recent advances in the understanding of the cancer process are due largely to the advent of molecular genetics and the use of monoclonal antibodies, and perhaps the greatest contribution of such techniques has been in studies of retinoblastoma. The occasional association of the familial predisposition to retinoblastoma with a visible chromosome deletion at $13 \mathrm{q} 14,{ }^{12-14}$ and the linkage to the gene coding for esterase$\mathrm{D},{ }^{1315}{ }^{16}$ confirmed the genetic basis for this disease. Epidemiological evidence led Knudson to formulate the 'two hit' hypothesis for the tumorigenesis of retinoblastoma, postulating that both copies of the viable gene must be inactivated by two independent mutational events (or 'hits'). ${ }^{16-18}$ An individual with the familial predisposition has inherited one inactive gene, such that only one subsequent mutational event is necessary, during the susceptible stage of embryonic development, to cause a retinoblast to become malignant. Retinoblastoma was the first cancer to be identified with a tumour suppressor gene, or anti-oncogene, ${ }^{13}$ to have this gene, RB1, located and cloned, and its protein product, p1 $10^{\mathrm{RB} 1}$, isolated. ${ }^{419}$ The inheritance is autosomally dominant in individuals with a single germline mutation due to the high probability of a second 'hit' inactivating the single remaining viable copy of the gene in one or more of the vulnerable retinoblasts. This malignancy is recessive at the genetic level, as indicated by the frequent loss of heterozygosity in tumour cells $^{1920}$ and reversal of the malignant phenotype in tumour derived cell lines fused with RB1 competent cells. ${ }^{21}$ Reversal of malignancy has also been reported in cell lines transfected with functional BR1 gene constructs. ${ }^{19}$ Recently, however, these results have been challenged by other researchers who have found incomplete reversal of malignancy in retinoblastoma cell lines, ${ }^{22}$ although such effects may be artefacts resulting from additional genetic changes having occurred in cells adapting to tissue culture environments. The importance of $\mathrm{RB} 1$ in malignant transformation has also been demonstrated by inactivating its product by association with virus proteins such as adenovirus $\mathrm{E} 1 \mathrm{~A},{ }^{23} \mathrm{SV} 40$ large $\mathrm{T}$ antigen $^{24}$ and papillomavirus E7 oncoprotein, ${ }^{25}$ both by transfection and transgenic manipulations. ${ }^{26}$ Furthermore, this gene has been implicated in the progression of other cancers, such as colon and breast carcinomas, and hence its significance as a tumour suppressor extends beyond its role in the tumorigenesis of retinoblastoma.

Perhaps the greatest recent clinical advance to emerge from theoretical studies of retinoblastoma, is in the field of prenatal and perinatal screening and genetic counselling. The predisposing gene for retinoblastoma may be identifed using DNA probes recognising restriction fragment length polymorphisms (RFLP, variable length fragments of DNA prepared by sequence dependent endonuclease activity) on Southern blot analyses of genomic DNA. ${ }^{12}$ This enables predisposed individuals to be identified in utero, as well as recognising carriers of the aberrant retinoblastoma gene in cases of incomplete penetrance. ${ }^{15}$

Monoclonal antibodies provide highly specific molecular recognition that can characterise and selectively localise tumour cells. To date their greatest contribution has been in elucidating the cellular origin of tumours, by equating immunohistochemical profiles in neoplastic cells with those of defined cell types in their tissue of origin. Although antibodies are highly specific for their molecular markers, the apparent lack of antigens expressed uniquely by cancer cells has limited their diagnostic and therapeutic applications. By identifying the inadequacies of monoclonal antibodies, researchers are now devising means of optimising their use in the clinical situation, and recent advances in recombinant technology may help in overcoming many of their limitations.

\section{Immunohistochemistry in defining cellular origin}

The immunochemical reactivity of tumour samples and cell lines such as $\mathrm{Y}^{27} 9^{27}$ and WERI $\mathrm{RB1}^{28}$ has been investigated using monoclonal antibodies which recognise markers associated with particular tissues and cell types. Such markers include retinal $S$ antigen, ${ }^{29-31}$ inter-retinoid binding protein, ${ }^{30}$ opsin, ${ }^{30}$ and rhodopsin,,$^{33}$ all associated with photoreceptors; S100 and glial fibrillary acidic protein ${ }^{30}{ }^{33} 34-37$ associated with glial cells; neuron specific enolase, ${ }^{30-32} 34-3638$ tetanus toxin and 
dopamine B hydroxylase, ${ }^{37}$ neurofilaments and synaptophysin, ${ }^{34-3639}$ all characteristic of neuronal cells. From the presence of these markers, a tumour origin from photoreceptors, glial, or neuronal cells has been postulated, as well as from a primitive common progenitor cell.

An alternative approach has been to equate antigenic heterogeneity with cell types, and therefore the differentiation potential of their common progenitor, the cell of origin of the tumour. By correlating with the known cell lineage of developing embryonic retinal cells, this allows definition of the tumour stem cell in terms of normal retinal progenitors (Figs 1, 2, and 3). Results from this work, ${ }^{40}$ and the weight of

\begin{tabular}{|c|c|c|c|}
\hline $\begin{array}{l}\text { Anti- } \\
\text { body }\end{array}$ & \begin{tabular}{|c} 
Retino- \\
blastoma
\end{tabular} & $\begin{array}{l}\text { Adult retina } \\
\text { NF GC. IP IN OP ON PR } \\
\end{array}$ & $\begin{array}{c}\text { Fetal retina } \\
\text { NF GC IP ONB C }\end{array}$ \\
\hline 包 & $\int_{0}^{9}$ & $\prod_{\omega} \phi+\infty+\hbar \omega$ & 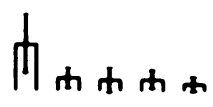 \\
\hline$\frac{+}{\frac{\sigma}{\infty}}$ & ${ }_{0}^{9}$ 円 & 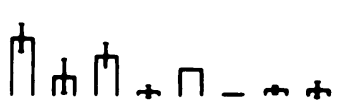 & $\prod_{\text {h }}$ \\
\hline 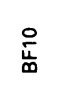 & $\int_{0}^{9}+$ & $\prod_{-+-\omega-\phi-}$ & $\prod_{x-\ldots}$ \\
\hline 景 & $\underbrace{9}_{0}$ 巾 & 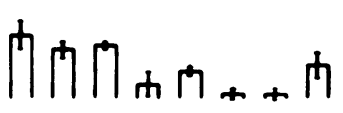 & 巾かか+円 \\
\hline$\underset{\tilde{N}}{\tilde{u}}$ & $\int_{0}^{9}$ & $-\ldots-\ldots$ 巾 & th内巾中 \\
\hline 产 & $\int_{0}^{9}$ 巾 & 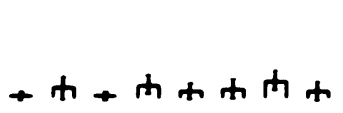 & 中内内内内 \\
\hline 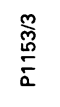 & $\int_{0}^{9} \phi$ & $-----\ldots$ & 内内内 \\
\hline
\end{tabular}

Figure 1 Immunohistochemical reactivity profiles of retinoblastoma, adult, and fetal retina with respect to seven differentially marking monoclonal antibodies. Tumour may be distinguished from normal retinal cell types using a panel of antibodies. $N F=$ nerve fibre, $G C=$ ganglion cell, $I P=$ inner plexiform, IN=inner nuclear, $O P=$ outer plexiform, $O N=$ outer nuclear, $P R=$ photoreceptor, $C=$ choroid $^{40}$

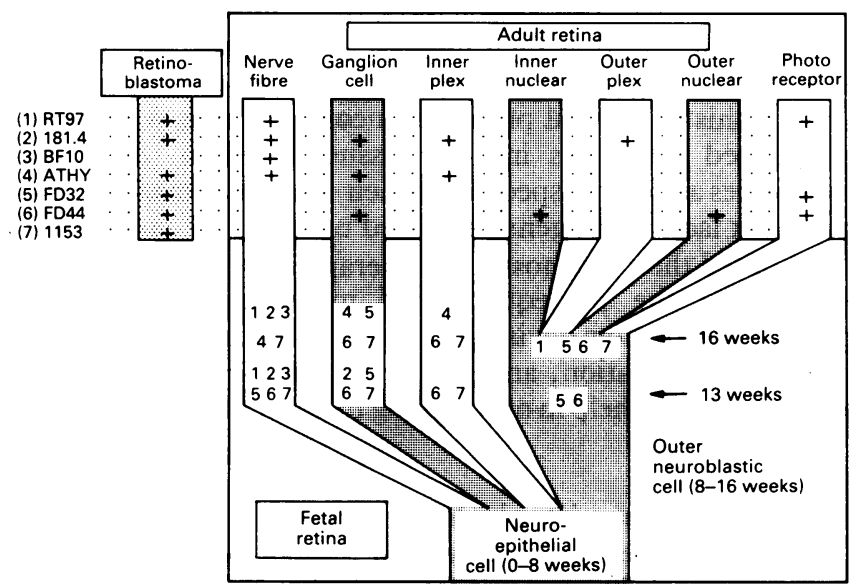

Figure 2 Immunohistochemical reactivity of retinoblastoma compared with adult and fetal retina, with respect to seven monoclonal antibodies. Positive retinoblastoma and adult retina reactivity denoted as $+;$ reactivity of 13 and 16 week retina is indicated by the number attributed to each monoclonal antibody. The tumour cell of origin is able to generate cell types expressing markers characteristic of both inner and outer retina. A stem cell with comparable differentiation potential is the neuroepithelial cell of 8 weeks' gestation. ${ }^{40}$ evidence from other studies, ${ }^{30} 3134$ 36-38 indicate that the tumour probably arises from a primitive multipotential neuroepithelial cell of early embryogenesis, and present in declining numbers into later stages of development. This would offer an ever shrinking target for Knudson's second 'hit', and account for the reduction in incidence with advancing age. Furthermore, if the second 'hit' is sustained when partial differentiation has already occurred, this may result in the less malignant form of the disease described as retinocytoma or retinoma. ${ }^{12}$

The use of histological sections of tumour tissue and established retinoblastoma cell lines present some difficulties in interpretation. The tumour may have incorporated nonneoplastic cells such as normal retinal and reactive glial cells, ${ }^{40}$ and cell lines of retinoblastoma are thought to be modulated extensively in tissue culture. In addition, cell lines may not possess the full differentiation capacity of the tumour stem cell, and are therefore not necessarily representative.

\section{Immunocytochemistry in differential diagnosis and prognosis}

There are a number of conditions which simulate retinoblastoma in presentation, including Coats' disease, persistent hyperplastic primary vitreous, and toxocariasis. ${ }^{41} \mathrm{Up}$ to $30 \%$ of eyes enucleated for suspected retinoblastoma have been misdiagnosed, ${ }^{42}$ and yet delayed treatment of the tumour resulting from ambiguous presentation may prove fatal. ${ }^{1}$ Accurate differential diagnosis is therefore essential if appro-

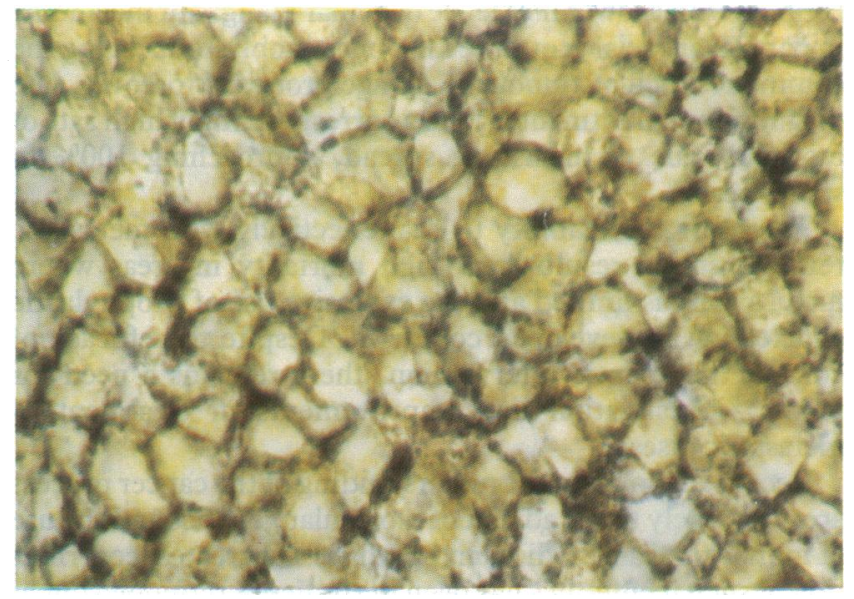

Figure $3 A$ Retinoblastoma reaction with anti-NCAM, UF13A; very strong cell membrane expression of this adhesion molecule (original magnification $\times 480$ ).

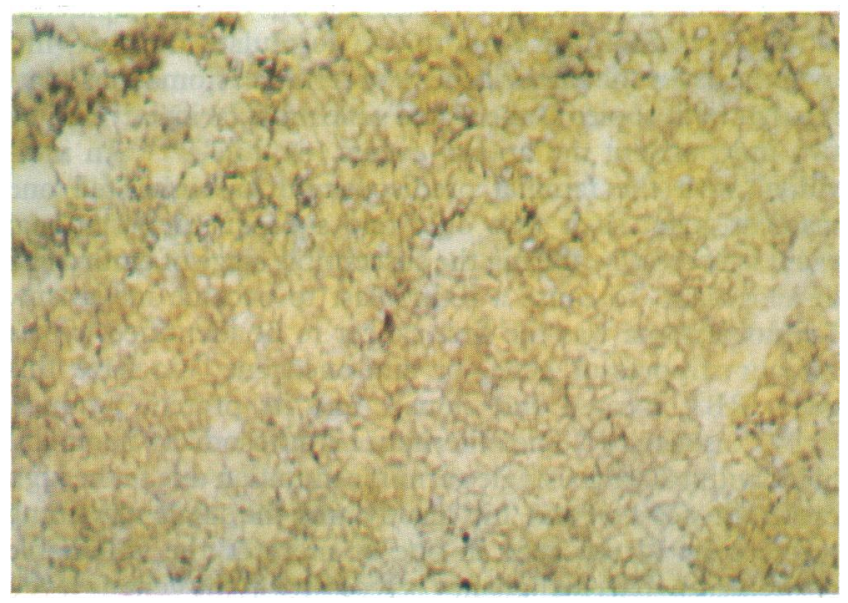

Figure 3B Retinoblastoma reaction with anti-L1 adhesion molecule, Uf 127.11; strong cell membrane expression (original magnification $\times 120$ ). 
priate treatment is to be given, and immunocytochemical procedures have a role to play in this.

The choice of therapy also rests upon an appraisal of the primary tumour progression, based on the Reese-Elsworth classification,,$^{413}$ and the presence or degree of metastatic

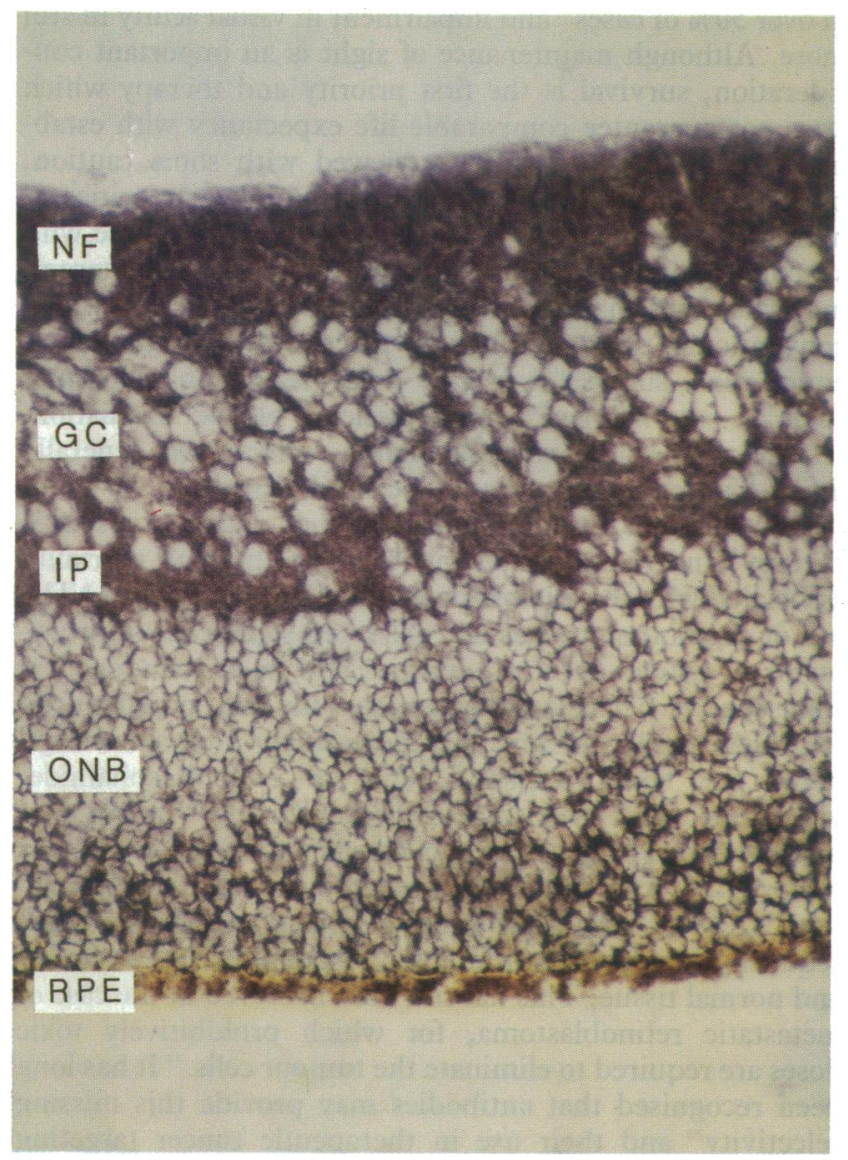

Figure 3C Sixteen week fetal retina reaction with anti-NCAM; very strong expression throughout all layers of the retina (original magnification $\times 165)$.

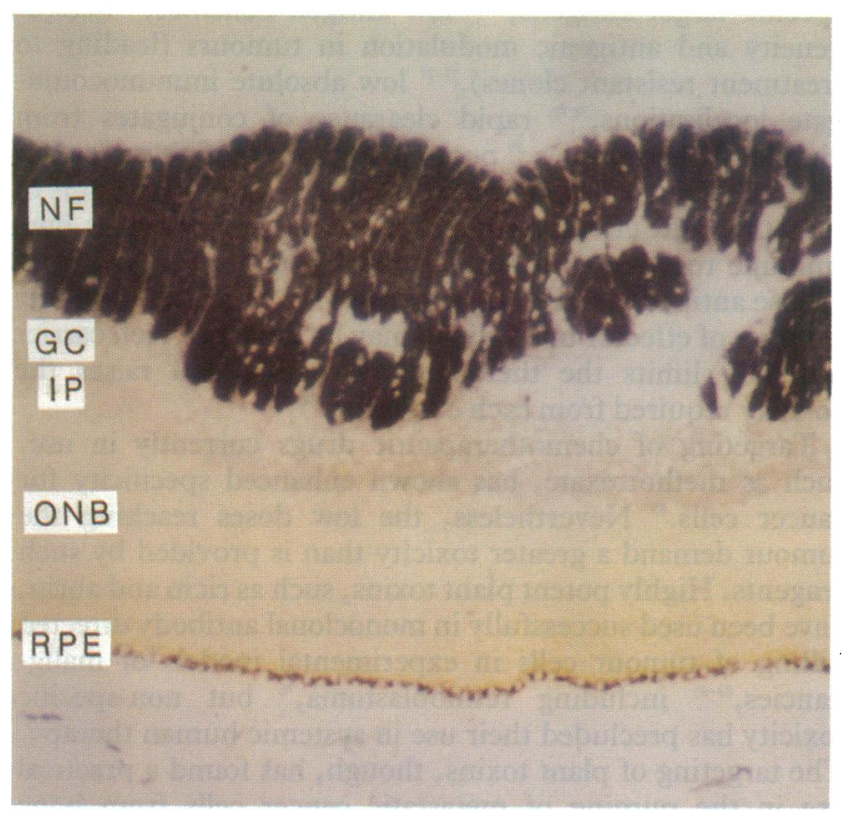

Figure $3 D$ Sixteen week fetal retina reaction with anti-L 1 ; inner retina reacts very strongly, but only weak expression in the outer retina (original magnification $\times 65)$. $N F=$ nerve fibre, $G C=$ ganglion cell, $I P=$ inner plexiform, $O N B=$ outer neuroblastic layer, $R P E=$ retinal pigment epithelium. dissemination. The use of monoclonal antibodies in identifying retinoblastoma cells, particularly at distal sites, is proving to be important in prognostic evaluation.

Ocular toxocariasis results from infestation of the eye with the larval stage of the dog ascarid Toxocara canis. Immunoassays using the serum of affected individuals are diagnostic for this disease in most cases, ${ }^{142}$ although this cannot be used to positively exclude retinoblastoma.

The reliability of diagnostic aqueous humour cytological assays following anterior chamber paracentesis, may be enhanced by the use of monoclonal antibodies. This may be important in confirmation of Coats' disease ${ }^{42}$ and in distinguishing between diffuse infiltrating retinoblastoma, requiring immediate enucleation, and inflammatory hypopyon associated with uveitis, where non-invasive examination by ultrasound or computed tomography may prove inconclusive. ${ }^{446}$ Similarly, the cytological analysis of fine needle biopsies may be improved by the use of immunocytochemical techniques, although possible tumour seeding in this procedure may limit its use. ${ }^{1}{ }^{467}$

The two main risk factors influencing prognosis that may be identified in enucleated eyes are optic nerve involvement, particularly at the resection margin, and trans-scleral extension. ${ }^{4849}$ Other factors which are generally indicative of terminal disease are central nervous system (CNS) involvement and bone marrow metastasis. ${ }^{50}$ Generally such features can be identified by conventional histological procedures, although their reliability and accuracy may be enhanced by immunohistochemical staining.

Immunohistological techniques may be used to detect small numbers of invasive retinoblastoma cells within the sclera, because they uniformly express determinants not associated with choroidal-scleral tissue or inflammatory cells. An example of this is neural cell adhesion molecule (NCAM), for which there are a number of specific monoclonal antibodies, including UJ13A ${ }^{4051}$ and ERIC-1. ${ }^{52}{ }^{53}$ Differentiation of optic nerve infiltration by retinoblastoma cells is more problematic, as many of the determinants which may potentially distinguish the tumour cells from surrounding neuronal tissue, such as anti-Thy $1,,^{40} 54$ or anti-opsin, ${ }^{30} 32$ are those which are not uniformly or consistently expressed by the tumour cells. This may be circumvented by applying staining to a sufficient number of invasive cells such that the subpopulation expressing the antigen in question is represented in the sample, or by using a panel of monoclonal antibodies on separate histological sections. ${ }^{40556}$ We have demonstrated that, by using such a panel of antibodies, it is possible to distinguish the tumour cells from individual cell types of adult and fetal retina by their immunoreactivities alone (Fig 1). These procedures require substantial tumour infiltration in order to provide sufficient tissue for analysis, in which case conventional techniques would probably prove adequate.

These and many other problems associated with the use of monoclonal antibodies would be resolved were a retinoblastoma specific antigen to be identified. Such a marker is proving elusive, not only in retinoblastoma but in other cancers, despite much investigation and many failed candidates. Researchers in our laboratories are presently engaged in a study isolating cell surface glycoproteins by lectin affinity, and separation by sodium dodecyl sulphate polyacrylamide gel electrophoresis in an effort to identify membrane components unique to retinoblastoma.

Cerebrospinal fluid (CSF) cytology, without the assistance of immunochemistry, has been used in assessing CNS involvement, ${ }^{57}$ although procedures may prove equivocal when trying to identify cells away from their original site, where normal histological clues are missing. Interpretation of these assays may again be helped by the use of monoclonal antibody panels, as has been utilised in identifying medulloblastoma and neuroblastoma cells in the CSF of 
patients with suspected neoplastic invasion of the meninges. ${ }^{58}$

Haematogenous metastasis of retinoblastoma to bone marrow is generally indicative of terminal disease, the only examples of successful treatment have made use of aggressive radiotherapy and chemotherapy combined with autologous transplant of purged marrow. ${ }^{57}$ It is important to identify accurately metastatic retinoblastoma cells in bone marrow in order to determine the most appropriate therapy, to monitor the course of the disease during remission or relapse, and to ensure that autologous transplant samples are free of tumour cells. Retinoblastoma cells individually resemble some mononuclear components of normal bone marrow, making definitive identification of tumour cells difficult. Immunocytochemistry has been used in a number of studies to identify accurately neuroblastoma cells in bone marrow aspirates and trephine biopsies, ${ }^{56} 59-61$ and such techniques are equally applicable to the recognition of metastatic retinoblastoma cells.

\section{Immunoscintigraphy in tumour imaging}

Perhaps the greatest use of antibody localisation in tumour diagnosis is in the field of immunoscintigraphy. For this procedure $\gamma$ emitters such as iodine-125, iodine-131, technetium-99m, or indium-111 are linked to monoclonal antibodies of maximal tumour selectivity, such as anticarcinoembryonic antigen. The reagents are administered systemically, and the image is read on a gammacamera. Early efforts at immunoscintigraphic imaging compared poorly with other non-invasive scanning techniques such as $x$ ray computed tomography, ultrasonography, and magnetic resonance imaging. Recent advances in $\gamma$ image enhancement, such as single photon emission computed tomography and computer subtraction of a second image obtained using nonantigenic protein interactions, have led to improved sensitivity and image clarity of immunoscintigraphy. ${ }^{62}$ This has allowed accurate and reliable imaging of such malignancies as colorectal carcinoma ( $73 \%$ predictive ${ }^{63}$ ), ovarian carcinoma $\left(67 \%\right.$ predictive $\left.^{64}\right)$, and thyroid carcinoma, ${ }^{65}$ and favourable comparisons with computed tomography and ultrasound..$^{6364}$

Primary ocular retinoblastoma is usually diagnosed as a result of clinical examination alone and the extent of the tumour is evaluated in a similar way. Differential diagnosis from simulating lesions often requires the use of ancillary tests, and orbital or optic nerve extension cannot be assessed readily by superficial examination. Typical characteristics of advanced ocular retinoblastoma are tumour necrosis and calcification, which may be identified by computed tomography scanning and ultrasonography, ${ }^{44}{ }^{46}$ and local extensions may be visualised further by magnetic resonance imaging. ${ }^{67}$ The success of such techniques in diagnosing and evaluating primary retinoblastoma has limited the application of immunoscintigraphy in imaging localised disease. There is potential for this technique, though, in evaluating metastatic progression where alternative scanning procedures may prove inadequate. Presently the technique is not considered reliable for secondary lesions of less than $1 \mathrm{~cm}^{3}$, and therefore micrometastases, which contribute greatly to the progression of this disease, may escape detection. On the other hand, non-specific localisations, which are a major limitation in therapeutic targeting, may in many cases be predicted and discounted.

It is possible that improvements in tumour localisation, with production of monoclonal antibodies of greater specificity, along with advances in imaging techniques, may lead to the application of immunoscintigraphy in the evaluation of metastatic retinoblastoma, although it is unlikely that this technique will ever have the sensitivity needed for identifying microscopic lesions. ${ }^{68}$

\section{Therapeutic uses of monoclonal antibodies}

A major factor inhibiting the use of new treatments in retinoblastoma, such as immunotherapy and antibody targeting, is the perceived high success rate with current treatments.

The survival rate of around $90 \%$ of cases in developed countries is achieved at the cost of the loss of one or both eyes in over $50 \%$ of cases ${ }^{41}$ and impairment in visual acuity in still more. Although maintenance of sight is an important consideration, survival is the first priority and therapy which does not guarantee comparable life expectancy with established treatment is justifiably viewed with some caution, presenting an ethical dilemma in the relative priorities of mortality and morbidity. ${ }^{6}$ This is particularly the case with speculative or experimental therapy, such as immunotargeting, when these have not been validated for cancers in which conventional treatment is less successful. In addition to enucleation, successful therapy relies heavily on techniques such as external beam and episcleral plaque irradiation, cryotherapy, and photocoagulation, which are generally limited in their applications to localised disease. ${ }^{41}{ }^{42}$

Disseminated retinoblastoma responds poorly to systemic therapy, and this greatly contributes to the high mortality associated with this disease once it is allowed to spread. ${ }^{6}$ The use of chemotherapy has not delivered significant improvements in patient survival, and has now been abandoned in some centres. ${ }^{669}$ Cyclophosphamide is the most popular drug for single agent therapy, but increasingly multiagent regimens are being applied, such as cyclophosphamide, vincristine, and Adriamycin (doxorubicin). ${ }^{10}$ Intrathecal methotrexate has also been applied when CNS involvement is indicated. ${ }^{63}$ The aim of chemotherapy is selective elimination of tumour cells while limiting damage to normal tissues, requiring an adequate differential response between tumour and normal tissue. This has not been achieved in the case of metastatic retinoblastoma, for which prohibitively toxic doses are required to eliminate the tumour cells. ${ }^{43}$ It has long been recognised that antibodies may provide this missing selectivity ${ }^{70}$ and their use in therapeutic cancer targeting remains a principal goal for oncologists. The promise of specific antibody directed cancer therapy has proved elusive,$^{7172}$ although the obstacles which must be overcome are now more clearly defined. These include a lack of tumour specific target antigens, ${ }^{73-75}$ low antigen densities, ${ }^{74}$ heterogeneity and antigenic modulation in tumours (leading to treatment resistant clones), ${ }^{73-77}$ low absolute immunoconjugate localisations, ${ }^{7879}$ rapid clearance of conjugates from circulation and tissues, ${ }^{75}$ poor penetration of high molecular weight reagents, ${ }^{75}$ non-specific retentions and interactions of targeting and effector components, and the patient's own immune reaction to foreign immunoglobulin (human antimouse antibody or HAMA response). ${ }^{78081}$ Furthermore, the number of effector units which may be linked to each carrier antibody limits the therapeutic targeting and raises the toxicity required from each conjugate. ${ }^{82}$

Targeting of chemotherapeutic drugs currently in use, such as methotrexate, has shown enhanced specificity for cancer cells. ${ }^{82}$ Nevertheless, the low doses reaching the tumour demand a greater toxicity than is provided by such reagents. Highly potent plant toxins, such as ricin and abrin, have been used successfully in monoclonal antibody directed killing of tumour cells in experimental models of malignancies, ${ }^{82-85}$ including retinoblastoma, ${ }^{76}$ but non-specific toxicity has precluded their use in systemic human therapy. The targeting of plant toxins, though, has found a practical use in the purging of metastatic cancer cells from bone marrow samples before autologous transplant. ${ }^{85}$

Purging of bone marrow samples may also be carried out by mechanical separation, using magnetic microsphere conjugates. This technique has been successfully applied in 
patients with haematogenous metastasis of retinoblastoma, using a cocktail of six monoclonal antibodies raised against neuroblastoma. ${ }^{\text {so }}$

Therapeutic use of antibody guided radionuclides is a natural extension of radioimmunoscintigraphy, and application of radiolabelled monoclonal antibodies has produced efficacious results in xenograft animal models of human malignancy.$^{86}{ }^{87}$ Systemic immunoradiotherapy of cancer in human patients has demonstrated consistently disappointing responses, due mainly to extremely low localisation of reagents, of the order of $0.001 \%-0.005 \%$ of injected dose per gram of tumour. ${ }^{78}{ }^{79}$ Furthermore, non-specific sequestration within untargeted viscera and retention of residues in the liver and kidneys have limited the tumour selectivity of intravenously applied reagents. For these reasons there has been interest in the direct application of antibody reagents to body cavities to treat compartmentalised tumours. Intraperitoneal instillation has been used to target ovarian carcinoma ${ }^{88}$ and both neoplastic meningitis and CNS leukaemia have been treated with intrathecal administration of iodine-131 labelled monoclonal antibody with promising results. ${ }^{7899}$ Intrathecal conjugate administration may also be applied to the treatment of CNS extension of retinoblastoma, presently associated with terminal disease, and results may be expected to be comparable with other secondary neoplastic meningeal disease.

Intraocular retinoblastoma is perhaps the most compartmentalised of all tumours, and as such may be amenable to the direct application of targeting monoclonal antibodies, particularly as the blood-retinal barrier may hinder systemic treatmènt is such cases. The lack of an adequate model of intraocular retinoblastoma has hampered investigation of such experimental therapies, but the recent development of a transgenic murine model ${ }^{26}$ may permit evaluation in primary disease.

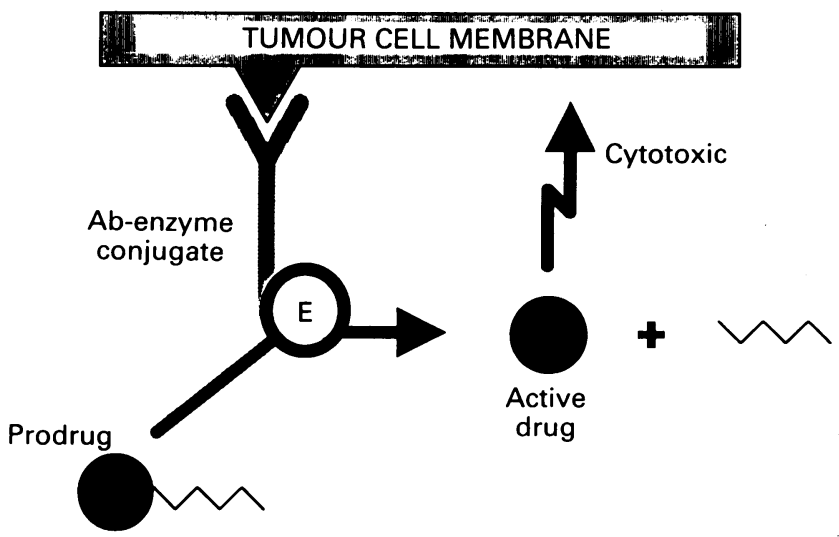

Figure 4 Antibody-directed enzyme prodrug therapy (ADEPT). Pretargeted antibody-enzyme conjugate is potentiated by application of prodrug, and generates active drug at the tumour site. ${ }^{92}$

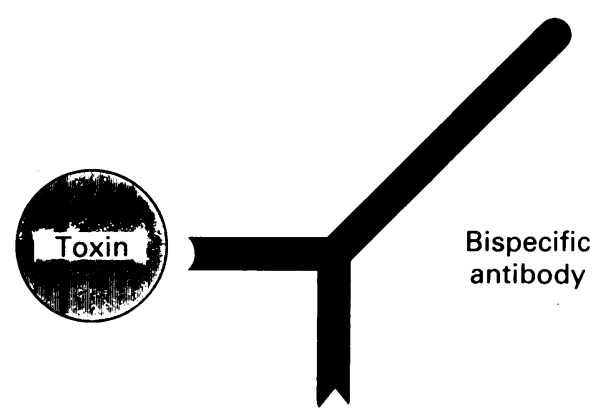

Tumour cell membrane Kt:

Figure 5 Bispecific monoclonal antibody in tumour targeting. ${ }^{84} 94$
Current studies in monoclonal antibody cancer targeting

Much of the current research into antibody-directed therapy is aimed at overcoming the limitations of targeting summarised above. Advances in such procedures may find application in the treatment of retinoblastoma, particularly metastatic disease.

In order to deliver toxic levels of reagents to tumours, a high dose must be applied, which in turn results in unacceptable accumulations in the blood and non-target tissues. These residues remain toxic until clearance of reagents is complete, during which time they are dose limiting. For this reason a number of research groups are looking at ways of achieving preclearance of unbound antibody before the application of the toxic component.

Antibody-directed enzyme prodrug therapy (ADEPT) delivers, via the monoclonal antibody component, an enzyme that remains non-toxic during conjugate clearance, and is potentiated only when a prodrug is administered; this is converted by the enzyme to an active drug at the tumour site (Fig 4). As clearance of the unbound delivery component is completed before the prodrug is applied, much higher concentrations of immunoconjugates may be given, with corresponding improvements in absolute levels of tumour localisation. Also, a potentially large number of prodrug molecules may be activated by a single enzyme, thus overcoming the numerical restriction which applies when the effector is directly conjugated to the delivery component..$^{7379192}$ Although the large molecular mass of enzyme conjugates may present problems of penetration for these reagents, the relatively small drug and toxin molecules generated by these enzymes will be able to diffuse far better than the targeted components themselves. This allows improved access by the effector component, and removes the necessity for each target cell to be individually localised.

An alternative approach aimed at pretargeting the tumour before potentiation by the effector component, makes use of the powerful and specific interaction between avidin and biotin (dissociation constant $10^{-15}$ ). The tumour localising monoclonal antibody is labelled with either avidin or biotin, and when clearance has established the optimum tumour/ blood and tumour/tissue ratios, the effector component is applied, linked to biotin or avidin respectively, and targeting is mediated by the affinity of two labelling molecules. The clearance rate of the biotin or avidin linked effector component is still significant, but is thought to be considerably faster than for the equivalent immunoconjugate, and may be accelerated by application of 'cold' avidin or biotin. ${ }^{93}$

The production of hybrid bispecific antibodies by fusing two hybridoma cell lines, ${ }^{84} 94$ or by combining monomeric Fab fragments, allows crosslinking of tumour cell surface antigens, bound by one Fab region, with a drug or toxin recognised by the other binding site ${ }^{169}$ (Fig 5). As previously, clearance of the targeting antibody may be achieved before the application of the effector component. Bispecific monoclonal antibodies may also be used to induce the patient's own immune response, by crosslinking tumour cells with activated $\mathrm{T}$ cells. ${ }^{94}$

A different two stage strategy is to pretarget the tumour with the non-radioactive boron-10 isotope, which remains harmless until irradiated with neutrons, when it disintegrates into high energy $\alpha$ particles. Enhancement of selectivity is achieved if irradiation can be confined to the tumour site. 95

These pretargeting techniques provide the potential of increased levels of tumour targeting, but the problems of antigen specificity, density, and modulation remain. Investigations being undertaken in our laboratories into binary enzyme targeting (BET) are attempting to address these problems. BET would be accomplished by delivering two different enzymes to malignant cells using monoclonal antibodies which recognise different tumour associated antigens. 
Both enzymes need to be present simultaneously in order to drive a two stage reaction activating a prodrug, or pretoxin, which is applied when the tumour/tissue ratio is optimal. In this way enhanced selectivity of targeting may be achieved by combining the specificities of both delivery monoclonal antibodies (Fig 6). As there are less stringent demands on individual antigen specificities, those expressed consistently, and at a higher density, may be selected as targets. ${ }^{52}$

The human anti-mouse antibody reaction presents severe limitations on repeat applications of therapy which utilises murine monoclonal antibodies, causing the reagents to be cleared so rapidly as to prevent adequate access to the target cells. ${ }^{779 \%}$ Systemic immunosuppression, using agents such as cyclosporin $\mathbf{A}$, or induction of specific tolerance to the monoclonal antibody by coupling with polyethylene glycol, may be helpful in reducing this reaction. ${ }^{79}$ Alternative

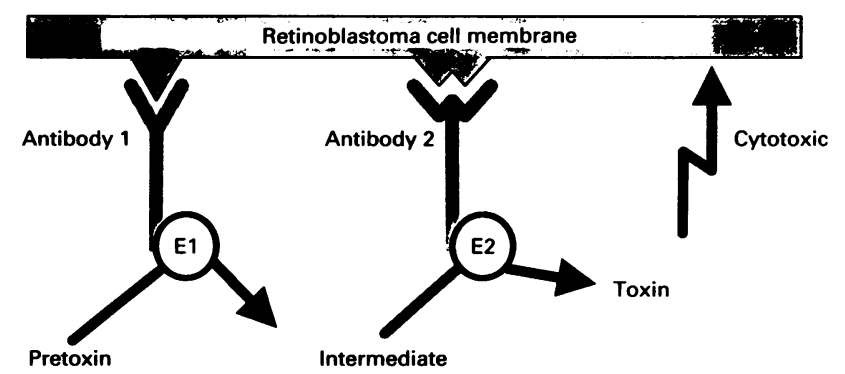

Figure 6 Binary enzyme targeted (BET) cytotoxicity. In situ generation of toxin requires the presence of two different cell surface markers. Each conjugate alone is non-toxic, and only the defined population of cells expressing both markers is targeted. ${ }^{2}$
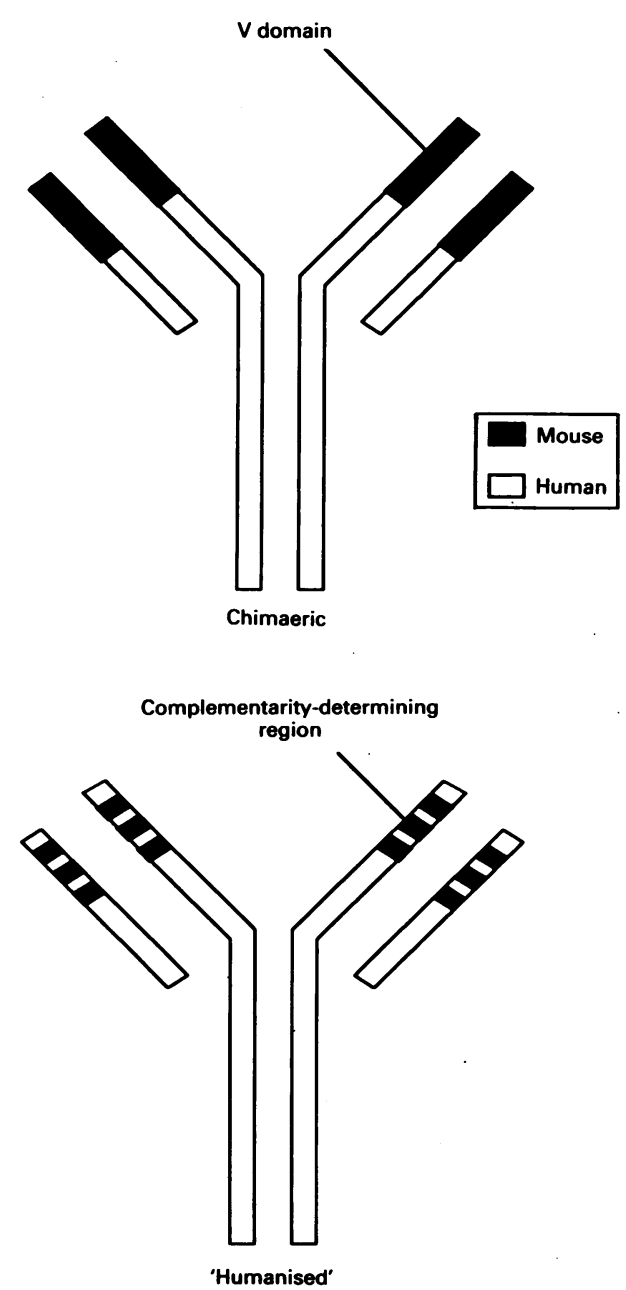

Figure 7 Chimaeric and 'humanised' monoclonal antibodies. ${ }^{82} 88$ strategies for minimising the impact of the human anti-mouse antibody reaction are to reduce or eliminate the murine component of the antibodies. This may be achieved by using human monoclonals, produced by hybridoma technology, or by transforming human peripheral B lymphocytes with Epstein-Barr virus. Practical and ethical problems preclude routine immunisations of human subjects, although in vitro alternatives are now available, and collection of sufficient numbers of specific B cells, as well as the lack of satisfactory fusion partners, restricts their application. An approach which is under extensive investigation, is to combine the low immunogenicity of human antibodies with the antigen specificity of mouse antibodies. This may be achieved either by producing chimeric antibodies, in which only the variable $(\mathrm{V})$ domains are of murine origin, or by engineering 'humanised' antibodies by recombinant DNA technology, which are entirely human except for the complementarity determining regions (CDRs) of the antigen binding site, which are defined by the gene sequences provided by the immunised mouse ${ }^{80} 81$ (Fig 7).

The problem of poor tumour localisation is aggravated by the limited penetration across blood-tissue barriers and into solid tumour masses. This problem may be addressed by the use of the antibody fragments; monomeric Fab or dimeric $\mathrm{F}\left(\mathrm{ab}^{\prime}\right)_{2}$. Not only are these fragments able to penetrate better in circumstances where molecular mass restricts tumour access, but they are also cleared more rapidly from the circulation, enhancing tumour/blood ratios, and do not interact with Fc receptors. ${ }^{79} \mathrm{~A}$ recent development is the production of recombinant engineered $\mathrm{Fv}$ antibody fragments, which are the smallest units retaining antigen-specific binding capability. ${ }^{79}$

Another possible approach is to improve penetration of reagents into tumours by modulating tissue barriers themselves. Increased blood flow can be induced in tumours by low doses of external radiation, by injection of complement fixing anti-tumour monoclonal antibodies, or by systemic or targeted application of cytokines. ${ }^{95}$ Accessibility to the intercellular space is influenced by a number of factors, including tight junctions formed by cell-cell interactions, and the presence of, and cellular adhesion to, basement membrane components. Cellular interactions are controlled chiefly by the expression of adhesion molecules, such as neural cell adhesion molecules (NCAMs) in retinoblastoma, and basement membranes interact via cell surface integrins. Access to intercellular spaces may be improved by blocking the activity of such molecules, utilising inhibitors or specific markers of adhesion molecules, such as the anti-NCAM monoclonal antibodies UJ13A, 5.1H11, A2B5, ${ }^{40}$ and ERIC-1. ${ }^{52}{ }^{53}$ Blocking of cellular adhesion may significantly increase metastatic potential of a tumour, therefore further investigation is needed before selecting appropriate reagents for therapeutic use.

An alternative to the use of monoclonal antibodies in specific delivery of therapeutic reagents, is to utilise conjugates of growth factors, hormone analogues, or integrin recognition motifs to target functional cell surface receptors. Many cancers originate through aberrant overexpression of growth factor receptors of the protein kinase family, due to proto-oncogene amplification, or the loss of control functions. Such possible oncogene associated targets include receptors for epidermal growth factor (oncogenes erb B, c-neu), colony stimulating factor (oncogene c-fms), stem cell factor (oncogene c-kit), and insulin (oncogene v-ros). ${ }^{9798}$ In addition, many cancers conserve or overexpress normal tissue hormone receptors - for instance, malignant melanoma expression of melanocyte stimulating hormone receptor. Targeting of receptors overexpressed in tumours may allow therapeutic delivery while minimising effects on development in normal tissues. The metastatic potential of malignant 
cells is dependent to a large extent upon particular cell-cell and cell-matrix interactions, and therefore cell adhesion molecules and integrins may present suitable targets for localisation using their native ligands or specific recognition motifs. It is unlikely that such targets would alone provide adequate specificity, but may be utilised in combination for BET, or used in compartmentalised administrations.

\section{Summary}

Monoclonal antibodies have had mixed fortunes since coming to the attention of the research and medical communities; disappointment at their failure to live up to early expectations has often obscured their real value. Understanding, and in some cases overcoming, their limitations has prompted a revival in interest based on their realistic potential.

Regulation of malignant characteristics, such as proliferation and dissemination, is a highly complex process involving interchange between growth factors and membrane bound receptors, cellular and matrix interactions, and enzyme mediated remodelling of the interstitial environment in favour of growth and invasion. There is likely to be increasing interest in immunohistochemical and western blot analyses of specific markers of malignancy, leading to greater understanding of tumour progression and metastasis, and antibody interactions may even provide means of modulating these processes. For example, we are currently engaged in a western blot evaluation of NCAM expression in retinoblastoma, and results indicate a link between tumour expression of low binding affinity embryonic type NCAMs and metastatic potential (unpublished data).

Progress in the therapeutic uses of monoclonal antibodies in retinoblastoma depend to a large extent on advances made in treating other malignancies, as it is only when clear benefits are demonstrable, in terms of patient survival and morbidity, that current low risk strategies will be abandoned. It is likely, therefore, that some of the prospective therapies, aimed at overcoming the limitations of inadequate specificity, inappropriate toxicity, and poor reagent localisation shall in time be applied to retinoblastoma.

Although the potential for tumour spread leads to prophylactic use of enucleation in developed countries, metastatic retinoblastoma is still regarded as a Third World problem. For this reason potential therapy aimed at controlling disseminated disease should be both inexpensive and readily portable for access to outlying regions. Providing cold storage facilities are available, monoclonal antibody conjugates are eminently portable; nevertheless, they are also extremely expensive to produce, limiting their use in circumstances in which there are great demands on meagre health care budgets. It is very important, therefore, to look into cheap and efficient new methods of production, such as prokaryote expression systems, in order to broaden their application in both the laboratory and the clinic. Furthermore, reagents and methodologies should be standardised so as to minimise requirement for expensive specialised equipment or training of personnel.

J F TARLTON D L EASTY

University of Bristol Department of Ophthalmology,

Bristol Eye Hospital,

Lower Maudlin Strol BS1 2LX

1 Stevenson KE, Hungerford J, Garner A. Local extraocular extension of retinoblastoma following intraocular surgery. $\mathrm{Br} \mathcal{f}$ Ophthalmol 1989; 73: retinoblasto 42.

2 Char DH, Wood IS, Huhta K, Rand N, Morita CT, Howes EL. Retinoblastoma: tissue culture lines and monoclonal antibody studies. Invest Ophthalmol Vis Sci 1984; 25: 30-40.

3 Griegel S, Hong C, Frotschl R, Hulser DF, Greger V, Horsthemke B, et al. Newly established human retinoblastoma cell lines exhibit an 'immortalised' but not an invasive phenotype in vitro. Int $\mathcal{F}$ Cancer 1990; 46: 125-32.
4 Gallie BL, Squire JA, Goddard A, Dunn JM, Canton M, Hinton D, et al. Biology of disease: mechanisms of oncogenesis in retinoblastoma. Lab Invest 1990; 62: 394-408.

5 Sanders BM, Draper GJ, Kingston JE. Retinoblastoma in Great Britain 1969-80: incidence, treatment, and survival. Br $\mathcal{Y}$ Ophthalmol 1988; 72 576-83.

6 White $\mathbf{L}$. Chemotherapy in retinoblastoma, current status and future directions. Am $\mathcal{F}$ Pediatr Hematol Oncol 1991; 13: 189-201.

7 Freedman J, Goldberg L. Incidence of retinoblastoma in the Bantu of South Africa. Brf Ophthalmol 1976; 60: 655.

8 Abiose A, Adido J, Agarwal SC. Childhood malignancies of the eye and orbit in northern Nigeria. Cancer 1985; 55: 2889-93.

9 Kodilinye HC. Retinoblastoma in Nigeria, problems of treatment. Am f Ophthalmol 1967; 63: 469-81.

10. Kayembe-Lubeji D. Retinoblastoma in Zaire. Tropical Doctor 1990; 20: 38

11 Bahakim HM, El-Idrissy IM. Epidemiological observations of consanguinity and retinoblastoma in Arabia. A retrospective study. Trop Geogr Med 1989; 41: $361-4$.

12 Benedict WF, Fung YKT, Murphree AL. The gene responsible for the development of retinoblastoma and osteosarcoma. Cancer 1988; 62: 1691-4.

13 Benedict WF, Murphree AL, Banerjee A, Spina CA, Sparkes MC, Sparkes RS Patient with 13 chromosome deletion: evidence that the retinoblastoma gene is a recessive cancer gene. Science 1983; 219: 973-5.

14 Francke U. Retinoblastoma and chromosome 13. Birth Defects 1978; 12: 131-7. 5 Cavenee WK, Murphree AL, Shull MM, Benedict WF, Sparkes RS, Kock E et al. Prediction of familial predisposition to retinoblastoma. N Engl f Med 1986; 314: 1201-7.

16 Hungerford $\mathrm{J}$. Recent advances in the understanding of retinoblastoma. Trans Ophthalmol Soc UK 1985; 104: 832-4.

17 Knudson AG. Mutation and cancer: statistical study of retinoblastoma. Proc Natl Acad Sci USA 1971; 68: 820-3.

18 Knudson AG. The genetics of childhood cancer. Cancer 1975; 35: 1022-6.
19 Lee W-H, Bookstein RE, Lee EYHP. Molecular biology of the human retinoblastoma gene. Immunol Ser 1990; 51: 169-200.

20 Cavenee WK, Hansen MF, Nordenskjold M, Kock E, Maumenee I, Squire JA, et al. Genetic origin of mutations predisposing to retinoblastoma. Science 1985; 228: 501-3.

21 Sasabe T, Inana G. Mechanism of suppression of malignancy in hybrids between Y79 retinoblastoma and NIH3T3 cells. Invest Ophthalmol Vis Sci 1991; 32: 2011-9.

22 Muncaster MM, Cohen BL, Phillips RA, Gallie BL. Failure of RB1 to reverse the malignant phenotype of human tumour cell lines. Cancer Res 1992; 52 654-61.

23 Whyte P, Buchkovich KJ, Horowitz JM, Friend SH, Raybuck M, Weinberg $\mathrm{RA}$, et al. Association between an oncogene and an anti-oncogene: the adenovirus E1A proteins bind to the retinoblastoma gene product. Nature 1988; 334: 124-9.

24 DeCaprio JA, Ludlow JW, Figge J, Shew J-Y, Huang C-M, Lee W-H, et al. SV40 large tumour antigen forms a specific complex with the product of the retinoblastoma susceptibility gene. Cell 1988; 54: 275-83.

25 Dyson N, Howley PM, Munger K, Harlow E. The human papillomavirus 16 E7 oncoprotein is able to bind to the retinoblastoma gene product. Science 1989; 243: 934-7.

26 O'Brian JM, Marcus DM, Niffenegger AS, Bernards R, Carpenter JL, Windle JJ, et al. Trilateral retinoblastoma in transgenic mice. Trans Am Ophthalmol Soc 1989; 87: 301-26.

27 Reid TW, Albert DM, Rabson AS, Russel P, Craft J, Chu E, et al. Characteristics of an established cell line of retinoblastoma. F Natl Cancer Inst 1974; 53: 347-60.

28 McFall RC, Sery TW, Makadon M. Characterisation of a new cell line derived from retinoblastoma. Cancer Res 1977; 37: 1003-7.

29 Mirshahi M, Boucheix C, Dhermy P, Haye C, Faure J-P. Expression of the photoreceptor-specific S-antigen in human retinoblastoma. Cancer 1986; 57: 1497-500.

30 Rodrigues MM, Wiggert B, Shields J, Donoso L, Bardenstein D, Katz N, et al. Retinoblastoma: immunohistochemistry and cell differentiation. Ophthalmotogy 1987; 94: 378-87.

31 Herman MM, Perentes E, Katsetos CD, Darcel F, Frankfurter A, Collins VP et al. Neuroblastic differentiation potential of the human retinoblastoma cell lines Y-79 and WERI-Rbl maintained in an organ culture system. Am f Pathol 1989; 134: 115-32.

32 Sun X, Yokoyama T, Minoda $\mathrm{K}$. Immunohistochemical studies of retinoblastoma. Fpn f Ophthalmol 1990; 34: 149-57.

33 Vrabeck T, Arbizo V, Adamus G, McDowell JH, Hargrave PA, Donoso LA Rod cell-specific antigens in retinoblastoma. Arch Ophthalmol 1989; 107: 1061-3.

34 Mesmer EP, Font RL, Kirkpatrick JB, Hopping W. Immunohistochemical demonstration of neuronal and astrocytic differentiation in retinoblastoma. Ophthalmology 1985; 92: 167-73.

35 Molnar ML, Stefansson K, Marton LS, Tripathi RS, Molnar GK. Immunohistochemistry of retinoblastoma in humans. Am $\mathcal{f}$ Ophthalmol 1984; 97 . 301-7.

36 Terengi G, Polak JM, Ballesta J, Cocchia D, Michetti F, Dahl D, et al. Immunocytochemistry of neuronal and glial markers in retinoblastoma. Virchows Arch (Pathol Anat) 1984; 404: 62-73.

37 Jaing Q, Lim R, Blodi FC. Dual properties of cultured retinoblastoma cells: immunohistochemical characterization of neuronal and glial markers. Exp Eye Res 1984; 39: 207-15.

38 Kyritsis AP, Tsokos M, Triche TJ, Chader GJ. Retinoblastoma - origin from a primitive neuroectodermal cell. Nature $1984 ; 307: 471-3$.

39 Kivela T, Tarkkanen A, Virtanen I. Synaptophysin in the human retina and retinoblastoma: an immunohistochemical and western blotting study. Invest Ophthalmol Vis Sci 1989; 30: 212-9.

40 Tarlton JF, Easty DL. The immunohistological characterisation of retinoblastoma and related ocular tissue. Br 7 Ophthalmol 1990; 74: 144-9.

41 Abramson DH. Retinoblastoma 1990: diagnosis, treatment and implications. Pediatr Ann 1990; 19: 387-95.

42 Shields JA, Shields CL, Parsons HM. Differential diagnosis of retinoblastoma. Retina 1991; 11: 232-43.

43 Donaldson SS, Smith LM. Retinoblastoma: biology and current management. Oncology 1989; 3: 45-51.

44 Abramson DH, Ellsworth RM. Ancillary tests for the diagnosis of retinoblastoma. Bull NYAcad Med 1980; 56: 221-31.

45 Girard B, Le Hoang P, D'Hermies F, Quere MA, Rousselie F. Le retinoblastome infiltrant diffus. F Fr Ophtalmol 1989; 12: 369-81. 
46 Char DH. Retinoblastoma diagnosis. In: Clinical ocular oncology. New York: Churchill Livingstone, 1989: 189-205.

47 Karcioglu ZA, Gordon RA, Karcioglu GL. Tumour seeding in ocular fine needle biopsy. Ophthalmology 1985; 92: 1763-7.

48 Kopelman JE, Mclean IW, Rosenberg SH. Multivariate analysis of risk factors for metastasis in retinoblastoma treated by enucleation. Ophthalmology 1987; 94: 371-7.

49 Karcioglu ZA, Haik BG, Gordon RA. Frozen section of the optic nerve in retinoblasoma surgery. Ophthalmology 1988; 95: 674-6.

50 Saleh RA, Gross S, Cassano W, Gee A. Metastatic retinoblastoma successfully treated with immunomagnetic purged autologous bone marrow transplantation. Cancer 1988; 62: 2301-3.

51 Allan PM, Garson JA, Harper EI, Asser U, Coakham HB, Brownell B, et al. Biological characterisation and clinical applications of a monoclonal antibody recognising an antigen restricted to neuroectodermal tissues. Int $\mathcal{f}$ Cancer 1983; 31: 591-8.

52 Tarlton JT, Easty DL. Investigation of selective binary targeted chemotherapy in disseminated and metastatic malignancy. $C$ lin Exp Metastasis 1992: 10:50.

53 Bourne SP, Patel K, Walsh F, Popham CJ, Coakham HB, Kemshead JT. A monoclonal antibody (ERIC-1), raised against retinoblastoma, that recognises the neural cell adhesion molecule (NCAM) expressed on brain and tumours arising from the neuroectoderm. $\mathcal{F}$ Neuro-oncol 1991; 10: 111-9.

54 Seeger RC, Danon YL, Raynor SA, Hoover F. Definition of a Thy-1 determinant on neuroblastoma, glioma, sarcoma and teratoma cells with a monoclonal antibody. F Immunol 1982; 128: 983-9.

55 Coakham HB, Garson JA, Allan PM, Harper EI, Brownell B, Kemshead JT, et al. Immunohistological diagnosis of central nervous system tumours using a monoclonal antibody panel. $\mathcal{F}$ Clin Pathol 1985; 38: 165-73.

56 Darbyshire PJ, Bourne SP, Allan PM, Berry J, Oakhill A, Keshead JT, et al. The use of a panel of monoclonal antibodies in pediatric oncology. Cancer 1987; 59: 726-30.

57 Abramson DH. Treatment of retinoblastoma. In: Blodi FC, ed. Retinoblastoma. New York: Churchill Livingstone, 1985: 63-93.

58 Coakham HB, Brownell B, Harper EI. Use of monoclonal antibody panel to identify malignant cells in cerebrospinal fluid. Lancet 1984; i: 1095-8.

59 Jonak ZL, Kennett RH, Bechtol KB. Detection of neuroblastoma cells in human bone marrow using a combination of monoclonal antibodies. Hybridoma 1982; 1 : 349-68.

60 Kemshead JT, Walsh F, Pritchard J, Greaves M. Monoclonal antibody to ganglioside GQ discriminates between haemopoietic cells and infiltrating neuroblastoma tumour cells in bone marrow. Int $\mathcal{F}$ Cancer 1981; 27: 447-52.

61 Kemshead JT, Fritschy J, Goldman A, Malpas JS, Pritchard J. Use of panels of monoclonal antibodies in the differential diagnosis of neuroblastoma and lymphoblastic disorders. Lancet 1983; i: 12-15.

62 Bradwell AR, Fairweather DS, Dykes PW. Developments in antibody imaging. In: Baldwin RW, Byers VS, eds. Monoclonal antibodies for cancer detection and therapy. London: Academic Press, 1985: 65-85.

63 Maguire RT, Schmelter RF, Pascucci VL, Conklin JJ. Immunoscintography of colorectal adenocarcinoma: results with site-specifically radiolabeled B72.3 ("In-CYT-103). Antibody, Immunoconjugates, and Radiopharmaceuticals 1989; 2: 257-69.
19.

64 Massuger LFAG, Kenemans P, Claessens RAMJ, Verheijen RHM, Schijf CPT, Strijk SP, et al. Immunoscintography of ovarian cancer with indium-111-labeled OV-TL3 $\mathrm{F}\left(\mathrm{ab}^{\prime}\right)_{2}$ monoclonal antibody. $\mathcal{f} \mathrm{Nucl}$ Med 1990; 31: 1802-10.

65 Zanin DEA, van Dongen A, Hoefnagel CA, Bruning PF. Radioimmunoscintography using iodine-131-anti-CEA monoclonal antibodies and thallium-201 scintography in medullary thyroid carcinoma: a case report. f Nucl Med 1990; 31: 1854-5.

66 Char DH, Hedges TR, Norman D. Retinoblastoma: CT diagnosis. Ophthalmology 1984; 91 : 1347-50.

67 Mafee MF, Goldberg MF, Cohen SB, Gotsis ED, Safran M, Chekuri L, et al. Magnetic resonance imaging versus computed tomography of leukocoric eyes and use of in vitro proton magnetic resonance spectroscopy of retinoand use of in vitro proton magnetic res

$68^{\circ}$ Sheidler J, Leinsinger G, Kirsch L-M, Sheiffarth OF, Stefani FH, Riedel KG. Immunoimaging of choroidal melanoma: assessment of its diagnostic accuracy and limitations in 101 cases. Br $\mathcal{F}$ Ophthalmol 1992; 76: 457-60.

69 Shields JA, Shields CL, Donoso LA, Lieb W. Current treatment of retinoblastoma. Trans Pen Acad Ophthalmol Otolaryngol 1989; 41: 818-22.

70 Ehrlich P. Proceedings of the 17th international congress of medicine (1913). In: Himmelweit F, ed. The collected papers of Paul Ehrlich. Vol 3. Oxford: Pergamon Press, 1960: 510. 71 Sikora K, Smedley H, Thorpe P. Tumour imaging and drug targeting. Br Med

72 Fischman AJ. When magic bullets ricochet. $f$ Nucl Med 1990; 31: 32-3.

73 Bagshawe KD. Cancer drug targeting. Clin Radiol 1985; 36: 545.

74 Hellstrom KE, Hellstrom I. Oncogene associated tumor antigens as taryets for immunotherapy. FASEB F 1989; 3: 1715.

75 Bagshawe KD. Towards generating cytotoxic agents at cancer sites. Brf Cancer 1989; 60: 275 .

76 Merriam JL, Lyon HS, Char DH. Toxicity of monoclonal $F\left(a b^{\prime}\right)_{2}:$ ricin-A conjugate for retinoblastoma in vitro. Cancer Res 1984; 44: 3178-83.

77 Ritz J, Pesando JM, Notis-McConarty J, Schlossman SF. Modulation of human acute lymphoblastic leukemia antigen induced by monoclonal antibody in vitro. F Immunol 1980; 125: 1506-14.

78 Moseley RP, Benjamin JC, Ashpole NM, Sullivan NM, Bullimore JA, Coakham HB, et al. Carcinomatous meningitis: antibody-guided therapy with I-131 HMFGl. I Neurol Neurosurg Psychiatry 1991; 54: 260-5.

79 Coakham HB, Richardson RB, Davies AG, Bourne SP, Eckert H, Kemshead JT. Neoplastic meningitis from a pineal tumour treated by antibody-guided JT. Neoplastic meningitis from a pineal tumour treated by antibody-gui
irradiation via the intrathecal route. Br f Neurosurg 1988; 2: 199-209.

80 Epenetos AA, Kosmas C. Monoclonal antibodies for imaging and therapy. Brf Cancer 1989; 59: 152-5.

81 Riechmann L, Clark M, Waldman H, Winter G. Reshaping human antibodies for therapy. Nature 1988; 332: 323-7. 82 Co MS, Queen C. Humanized antibodies for therapy. Nature 1991; 351:

83 Embleton MJ, Garnett MC. Antibody targeting of anti-cancer agents. In: Baldwin RW, Byers VS, eds. Monoclonal antibodies for cancer detection and therapy. London: Academic Press, 1985: 1317-44.

84 Embleton MJ, Charleston A, Robins RA, Pimm MV, Baldwin RW. Recombinant ricin toxin $\mathrm{A}$ chain cytotoxicity against carcinoembryonic antigen nant ricin toxin A chain cytotoxicity against carcinoembryonic antigen expressing tumour cells mediated by a bispecific monoclonal antibod
potentiation by ricin toxin $\mathrm{B}$ chain. $\mathrm{Br} \mathcal{F}$ Cancer $1991 ; 63: 670-4$.

85 Ito T, Qiu H, Collins JA, Brill AB, Johnson DK, Griffin TW. Preclinical assessments of ${ }^{\circ} \mathrm{Y}$-labeled $\mathrm{Cl} 10$ anti-carcinoembryonic antigen immunotoxin: a therapeutic immunoconjugate for human colon cancer. Cancer Res 1991; 51: 255-60.

86 Vitetta ES, Krolick KA, Miyama-Inaba M, Cushley W, Uhr JW. Immunotoxins: a new approach to cancer therapy. Science 1983; 219: 644-50.

87 Lee YS, Bullard DE, Zalutsky MR, Coleman RE, Wickstrand CJ, Friedman HS, et al. Therapeutic efficacy of antiglioma mesenchymal extracellular matrix ${ }^{131}$ I-radiolabeled murine monoclonal antibody in a human glioma Xenograft model. Cancer Res 1988; 48: 559-66.

88 Colcher D, Roselli M, Molinolo A, Schlom J. Radioimmunotherapy using monoclonal antibodies reactive with a tumour associated antigen (TAG-72). monoclonal antibodies reacti

89 Epenetos AA, Hooker G, Krausz T, Snook D, Bodmer WF, TaylorPapadimitriou J. Antibody-guided irradiation of malignant ascites in ovarian cancer: a new therapeutic method possessing specificity against cancer cells. Obstet Gynecol 1986; 68: 71S-74S.

90 Pizer B, Papanastassiou V, Hancock J, Cassano W, Coakham H, Kemshead J. A pilot study of monoclonal antibody targeted radiotherapy in the treatment of central nervous system leukemia in children. $\mathrm{Br} \mathcal{F}$ Haematol 1991; 77: 466-72.

91 Connors TA. Has chemotherapy anywhere to go? Cancer Surv 1989; 8: 693705.

92 Connors TA. Antibody-directed enzyme prodrug therapy. Cancer Cells 1990; 2: 56-7.

93 Paganelli G, Malcovati M, Fazio F. Monoclonal antibody targeting techniques for tumour localisation: the avidin-biotin system. Nucl Med Commun 1991; 12: $211-34$.

94 Clark M, Waldmann H. Therapy with hybrid antibodies. Brf Cancer 1989; 59: 304

95 Mach J-P, Pelegrin A, Buchegger F. Imaging and therapy with monoclonal antibodies in non-hematopoietic tumours. Curr Opin Immunol 1991; 3: 685-93.

96 Schlom J, Milenic DE, Roselli M, Colcher D, Bird R, Johnson S, et al. New concepts in monoclonal antibody based radioimmunodiagnosis and radioimmunotherapy in carcinoma. Nucl Med Biol 1991; 18: 425-35.

97 Rayter SI, Iwata KK, Michitsch RW, Sorvillo JM, Valenzuela DM, Foulkes JG. Biochemical functions of oncogenes. In: Glover DM, Hames BD, eds. Oncogenes. Oxford: Oxford University Press, 1989: 113-89.

98 Gullick WJ. Prevalence of aberrant expression of the epidermal growth factor receptor in human cancers. Br Med Bull 1991; 47: 87-98. 